Article

\title{
Thermoelectric Properties of Zinc-Doped Indium Tin Oxide Thin Films Prepared Using the Magnetron Co-Sputtering Method
}

\author{
Ho Yun Lee ${ }^{1}$, Im Jeong Yang ${ }^{2}$, Jang-Hee Yoon ${ }^{3}$, Sung-Ho Jin ${ }^{4}$, Seohan Kim ${ }^{5, *}$ and \\ Pung Keun Song ${ }^{1, *}$ \\ 1 Department of Materials Science and Engineering, Pusan National University, Busan 46241, Korea; \\ dbs0770@pusan.ac.kr \\ 2 Department of Physics, Pusan National University, Busan 46241, Korea; hsyang@pusan.ac.kr \\ 3 Busan Center, Korea Basic Science Institute, Busan 46742, Korea; jhyoon@kbsi.re.kr \\ 4 Department of Chemistry Education, Graduate Department of Chemical Materials, and Institute for Plastic \\ Information and Energy Materials, Pusan National University, Busan 46241, Korea; shjin@pusan.ac.kr \\ 5 Materials Technology Research Institute, Pusan National University, Busan 46241, Korea \\ * $\quad$ Correspondence: seohahnkim@gmail.com (S.K.); pksong@pusan.ac.kr (P.K.S.); Tel.: +82-051-510-3579 (P.K.S.)
}

Received: 23 October 2019; Accepted: 21 November 2019; Published: 24 November 2019

\begin{abstract}
The thermoelectric properties of In-Sn-O (ITO) thin films were estimated in relation to microstructures with various zinc concentrations. The zinc-doped ITO (ITO:Zn) thin films were amorphized with increasing zinc concentration. The carrier density $(n)$ of the thin films decreased as the zinc content increased, which could be attributed to a decline in oxygen vacancies. The highest Seebeck coefficient $(S, 64.91 \mu \mathrm{V} / \mathrm{K})$ was obtained with an ITO film containing 15.33 at.\% of $\mathrm{Zn}$ due to the low $n$ value, which also exhibited the highest power factor $\left(234.03 \mu \mathrm{W} \mathrm{K}{ }^{-2} \mathrm{~m}^{-1}\right)$. However, the highest thermoelectric figure of merit value (0.0627) was obtained from the film containing 18.26 at.\% of $\mathrm{Zn}$ because of both low $n$ and the lowest thermal conductivity $(\kappa)\left(1.085 \mathrm{~W} \mathrm{~m}^{-1} \cdot \mathrm{K}^{-1}\right)$. The total $\kappa$ decreased as increasing zinc concentration in the thin films. It was confirmed that the decrease of total $\kappa$ was dominated by electron $\mathcal{\kappa}$ rather than lattice $\kappa$.
\end{abstract}

Keywords: zinc-doped In-Sn-O thin film; thermal conductivity of thin film; transparent amorphous oxide semiconductor; magnetron co-sputtering; thermoelectric figure of merit (ZT)

\section{Introduction}

In recent times, thermoelectric (TE) energy-harvesting technologies have attracted significant attention as alternative energy, as they demonstrate the possibility of generating eco-friendly electric power that is not dependent on fossil fuel [1-6]. Therefore, several studies have focused on TE materials for achieving power generation without mechanical movements, and for converting waste heat into electric power with Seebeck effects [1-6]. In addition, heating issues have been developing recently in electronic equipped displays, such as smartphones, televisions, and tablet personal computers, owing to their integrated structures and an increase of current density. Such issues can also shorten the devices' lifetimes and result in energy-efficiency loss $[7,8]$. Therefore, it is necessary to research TE materials to resolve such heating problems. The performance of TE materials is generally estimated using the TE figure of merit (ZT). Such an estimation is important for fabricating high-efficiency TE materials. ZT is defined using Equation (1) as follows [4]:

$$
\mathrm{ZT}=\frac{S^{2} T}{\rho \kappa}=\frac{S^{2} \sigma}{\kappa_{e}+\kappa_{l}} \mathrm{~T}
$$


where $S, \rho, \kappa, \sigma, \kappa_{e}, \kappa_{l}$, and $T$ represent the Seebeck coefficient, resistivity, thermal conductivity, electrical conductivity, electron thermal conductivity, lattice thermal conductivity, and absolute temperature, respectively. As defined in Equation (1), a high $\sigma$ and a low $\kappa$ are required to achieve a high ZT [9].

There are various kinds of TE materials, such as bulk-type materials, thin films, nanoparticles, and nanorods with their form. The bulk-type TE materials have been used for power generation, as they can generate substantial amounts of converted energy, which can be applied in electronic equipment, such as refrigerators and air conditioners $[7,8]$. However, it is difficult to employ these materials in miniaturized electronic devices because of their large volumes. Therefore, thin-film TE materials can be used in these miniaturized devices for precisely controlling the temperature. These TE materials can enable the building of nanostructures that can be connected to small devices. Among these thin-film TE materials, oxide semiconductors, such as $\mathrm{SnO}_{2}, \mathrm{ZnO}$, and $\operatorname{In}_{2} \mathrm{O}_{3}$, have attracted attention due to their high thermal stability, relatively low price, and non-toxicity compared to telluride TE materials, such as $\mathrm{Bi}-\mathrm{Te}$ and $\mathrm{Pb}-\mathrm{Te}$ [4,10-14]. These semiconductors have been studied for developing high-efficiency thin-film TE materials. Among them, $\mathrm{In}_{2} \mathrm{O}_{3}$ has been studied and used for a long time as a transparent electrode for display, solar cell, and touchscreen panels because of its high optical transmittance $(>80 \%$ at $550 \mathrm{~nm})$ and high $\sigma(>2000 \mathrm{~S} / \mathrm{cm})[15-17]$.

Figure 1 shows the ZT values from the latest research on oxide semiconductors, including the results from this study. The ZT values from the latest research are measured at various temperatures. In order to help comparison, they are standardized to $300 \mathrm{~K}[14,18-29]$. It is confirmed that the crystalline-structured oxide TE materials demonstrate low ZT values due to their high $\kappa_{l}$, despite their low sheet resistance. In general, sputtered thin films demonstrate low TE properties due to their preferentially oriented growth, which results in a high $\kappa_{l}$ value. However, these thin films can easily control the microstructure in relation to deposition conditions, such as deposition power, pressures, and doping impurities. Therefore, it is possible to achieve a high $\sigma$ as well as a low $\kappa$ simultaneously, through high mobility $(\mu)$ and low carrier density $(n)$. In previous studies, we confirmed that the amorphization of conductive oxide thin film can improve the ZT value without degrading the electrical and optical properties [24].

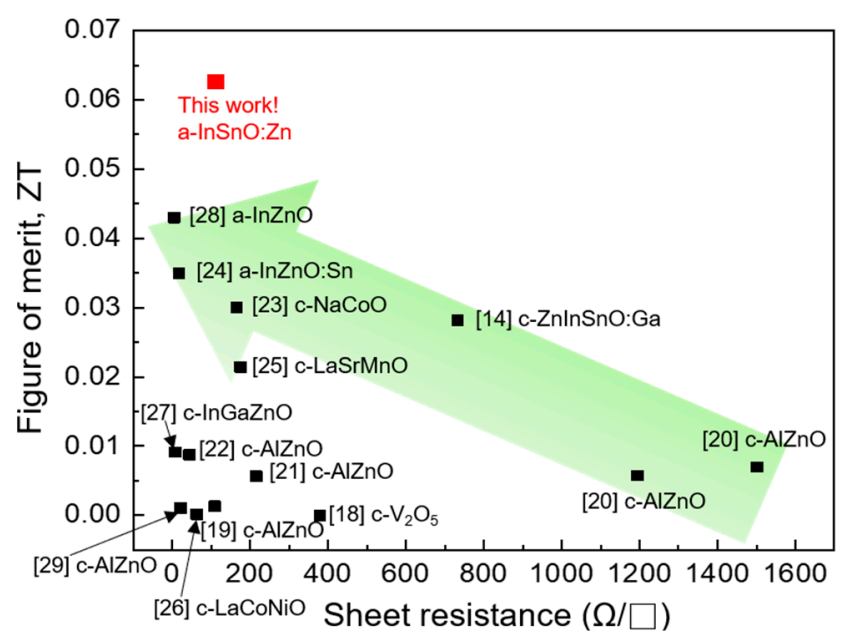

Figure 1. Thermoelectric figure of merit (ZT) values from previous studies and our results as a function of sheet resistance. The ZT values from the latest research are measured at different temperatures. In order to help comparison, they are standardized to $300 \mathrm{~K}$.

Based on these backgrounds, in this study, we amorphized the thin films to achieve a low $\kappa$ value by controlling $n$ with various zinc concentrations. 


\section{Experimental Detail}

Thin films with a thickness of $150 \mathrm{~nm}$ were deposited on the non-alkali glass through magnetron co-sputtering using two cathodes, comprising a direct current (DC) cathode equipped with an In-Sn-O (ITO) $\left(\mathrm{SnO}_{2}: 10 \mathrm{wt} . \%\right)$ target, and a radio frequency (RF) cathode equipped with the $\mathrm{ZnO}$ target, without substrate heating. The base pressure was set to $2.0 \times 10^{-3} \mathrm{~Pa}$, and the total gas pressure was set to $1.0 \mathrm{~Pa}$ using an Ar gas flow of $20 \mathrm{sccm}$. The RF power was varied from 0 to $160 \mathrm{~W}$ under a constant DC power of $150 \mathrm{~W}$. Before the deposition, pre-sputtering was performed for $5 \mathrm{~min}$ to eliminate the impurities on the target surface. The thickness and deposition rate of the films were determined using a spectral reflectometer (ST2000-DLXn, K-MAC, Daejeon, Korea). The optical properties were measured by a UV-visible spectrometer (SHIMADZU, UV-1800, Kyoto, Japan). The electrical properties of the thin films were measured using the Hall Effect measurement system (HMS-3000, Ecopia, Anyang, Korea), and their crystallinity was measured through X-ray diffraction (XRD, Bruker HADDS, $\mathrm{Cu}-\mathrm{K} \alpha$ radiation at $40 \mathrm{kV}, 40 \mathrm{~mA}, \theta-2 \theta$ mode). The zinc concentrations in the ITO:Zn thin films were estimated using a high-performance X-ray photoelectron spectrometer (K-ALPHA+ X-ray photoelectron spectroscopy (XPS) system, Thermo Fisher Scientific, Loughborough, UK). The X-ray source was $\mathrm{Al} \mathrm{K \alpha}(\mathrm{h} v=1486.6 \mathrm{eV})$, and the $\mathrm{X}$-ray energy was $12 \mathrm{kV}$ at $72 \mathrm{~W}$. The $S$ and PF (power factor) values of the thin films were calculated. The $\kappa$ value of thin films was measured using the time-domain thermoreflectance method [30]. David G. Cahill et al. shows a schematic diagram of the time-domain thermoreflectance (TDTR) method [31]. The ITO:Zn thin films were coated with aluminum $(85 \mathrm{~nm})$. The Ti:Sapphire laser was used for TDTR measurement. The Fourier transform-infrared spectroscopy (FT-IR) measurements were performed on a Vertex 80v and Hyperion (Bruker) in the range of $650-4000 \mathrm{~cm}^{-1}$.

\section{Results and Discussion}

Figure 2a shows the XRD patterns of the ITO:Zn thin films deposited with varied ZnO RF powers (W) without intensive heating. The thin films prepared without zinc doping demonstrate a crystalline structure, and the ITO:Zn films are amorphized after the RF power of $20 \mathrm{~W}$. Figure $2 \mathrm{~b}$ and Table 1 show X-ray photoelectron spectroscopy (XPS) analysis of the metal concentrations (In, Sn, and Zn) in ITO thin films as a function of ZnO RF power (W). The amounts of In and Sn are decreased in relation to $\mathrm{ZnO} R F$ power while the ratio of $\mathrm{Sn} / \mathrm{In}$ is constant. The zinc content in the ITO monotonously increases as a function of the $\mathrm{ZnO} R F$ power indication, and, therefore, the zinc content is effectively controlled by changing the RF deposition power. The ITO:Zn thin films are amorphized when the RF power is $20 \mathrm{~W}$, and it is confirmed that the zinc content in thin films is 1.56 at.\%. In addition, ITO:Zn demonstrated high transmittance in the visible-wavelength region (>85\% at $550 \mathrm{~nm}$ ).

The variation in the electrical properties of the ITO:Zn thin films in relation to the zinc content is shown in Figure 3. The lowest resistivity $\left(\rho, 5.668 \times 10^{-4} \Omega \cdot \mathrm{cm}\right)$ was obtained when the zinc content was 0.44 at.\%. The resistivity is defined using Equation (2) as follows:

$$
\rho=\frac{1}{n e \mu}
$$

where $n, e$, and $\mu$ are carrier density, electron charge, and hall mobility, respectively. The variations in $\rho$, therefore, can be explained by $n$ and $\mu$. The value of $n$ decreased with higher zinc content, whereas that of the thin film at the zinc content value of 0.44 at.\%. The increase in $n$ can be attributed to the interstitial $\mathrm{Zn}^{1+}$, which is one of the carrier formation mechanisms of $\mathrm{ZnO}$ that provides electrons in the lattice [32,33]. The decrease in $n$ could be related to $\mathrm{Zn}^{2+}$ being substituted for $\operatorname{In}^{3+}$ as the acceptor or $\mathrm{Sn}^{4+}$ in the ITO films and oxygen vacancies [34-39]. It was observed that $\mu$ decreased when the zinc content was over $2.80 \mathrm{at} . \%$. This resulted from the decline in oxygen vacancies, which are at the center of ionization scattering. 
Figure 4 a shows $S$ and $n$ for the as-deposited ITO:Zn thin films. $S$ is defined using Equation (3) as follows [24]:

$$
S=\frac{8 \pi^{2} k_{B}^{2}}{3 e h^{2}}\left(\frac{\pi}{3 n}\right)^{\frac{2}{3}} m^{*} T
$$

where $k_{\mathrm{B}}, h, m^{*}$, and $n$ represent the Boltzmann constant, Plank's constant, effective mass, and carrier density, respectively. The Seebeck coefficient $(S)$ is estimated by measuring Seebeck voltage under a temperature gradient, or calculated from Equation (3). In the second method, the accurate value can be obtained if the effective mass is correctly measured. In the case of the present work, the effective mass value $\left(5.22624 \times 10^{-35} \mathrm{\mu} / \mathrm{cm}^{2}\right)$ has been accurately calculated in previous work [24,28]. It was observed that $S$ increased with an increase in the zinc content up to 15.33 at.\%, after which it declined marginally (18.26 at.\%). The highest $S(64.91 \mu \mathrm{V} / \mathrm{K})$ value was obtained when the zinc content was 15.33 at.\%, as $S$ is inversely proportional to $n$.

(a)

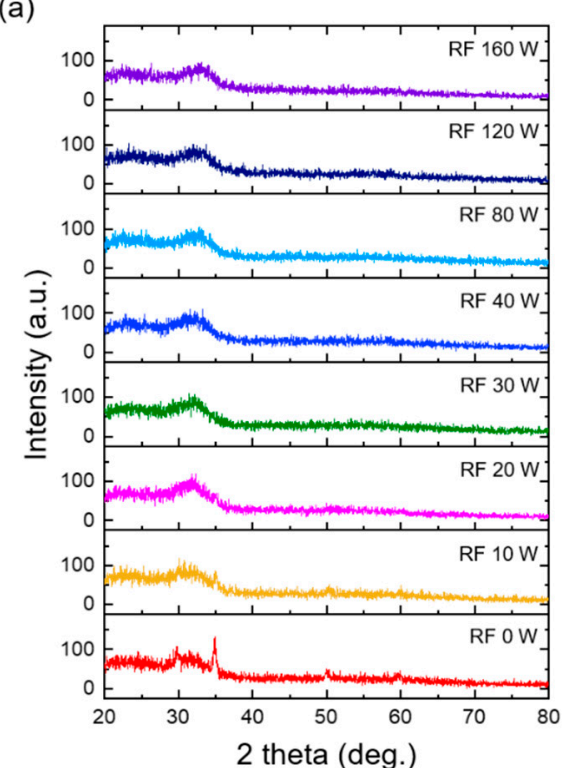

(b)

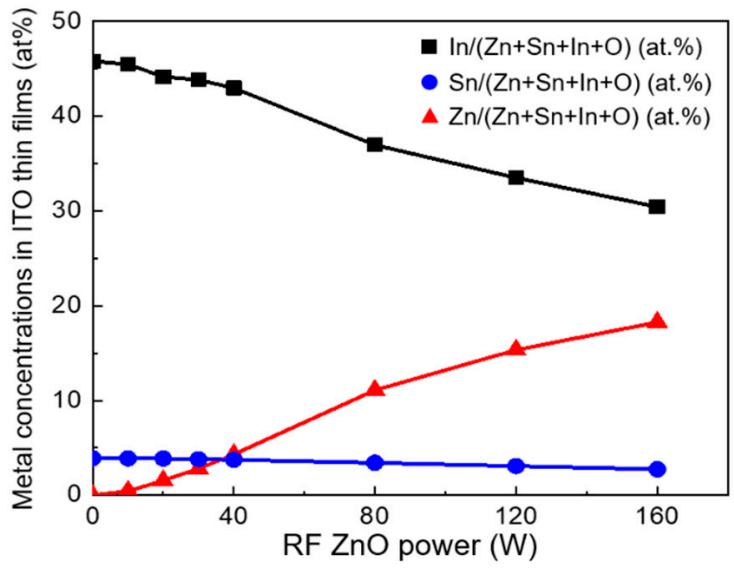

Figure 2. (a) X-ray diffraction (XRD) patterns of In-Sn-O (ITO) thin films against varied zinc concentrations, and (b) X-ray photoelectron spectroscopy (XPS) analysis of the metal concentrations (In, $\mathrm{Sn}$, and $\mathrm{Zn}$ ) in ITO thin films as a function of $\mathrm{ZnO}$ radio frequency (RF) power (W).

Table 1. X-ray photoelectron spectroscopy (XPS) analysis of the metal concentrations (In, Sn, and Zn) in ITO thin films as a function of $\mathrm{ZnO}$ RF power (W).

\begin{tabular}{ccccccccc}
\hline RF ZnO Power $(\mathbf{W})$ & $\mathbf{0}$ & $\mathbf{1 0}$ & $\mathbf{2 0}$ & $\mathbf{3 0}$ & $\mathbf{4 0}$ & $\mathbf{8 0}$ & $\mathbf{1 2 0}$ & $\mathbf{1 6 0}$ \\
\hline $\mathrm{In} /(\mathrm{Zn}+\mathrm{Sn}+\mathrm{In}+\mathrm{O})($ at.\%) & 45.81 & 45.48 & 44.17 & 43.85 & 42.98 & 36.97 & 33.51 & 30.45 \\
$\mathrm{Sn} /(\mathrm{Zn}+\mathrm{Sn}+\mathrm{In}+\mathrm{O})($ at.\%) & 3.91 & 3.89 & 3.88 & 3.8 & 3.75 & 3.42 & 3.08 & 2.75 \\
$\mathrm{Zn} /(\mathrm{Zn}+\mathrm{Sn}+\mathrm{In}+\mathrm{O})($ at.\%) & 0 & 0.44 & 1.56 & 2.8 & 4.31 & 11.09 & 15.33 & 18.26 \\
\hline
\end{tabular}




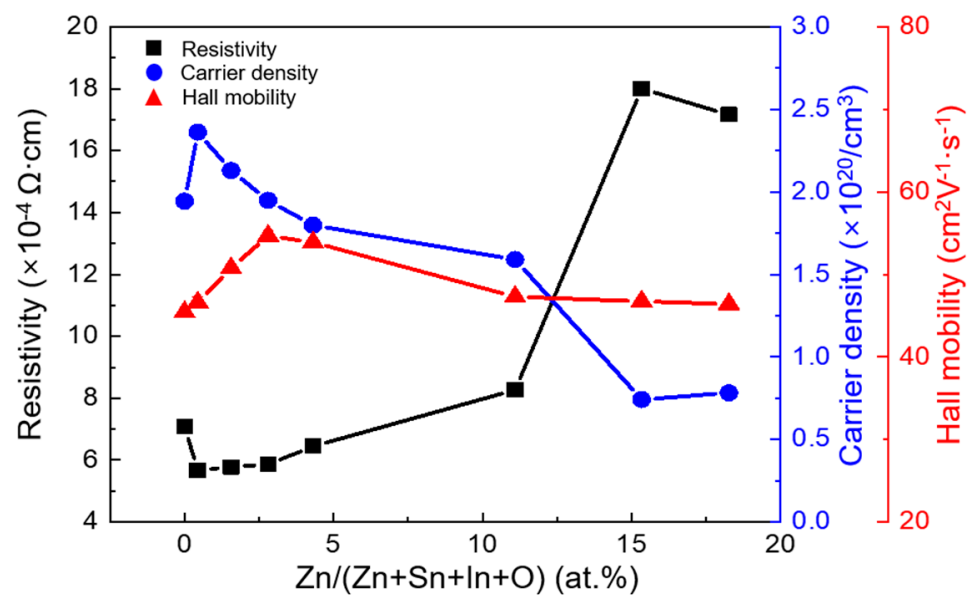

Figure 3. Resistivity, carrier density, and hall mobility of ITO:Zn thin films in relation to zinc content.

(a)

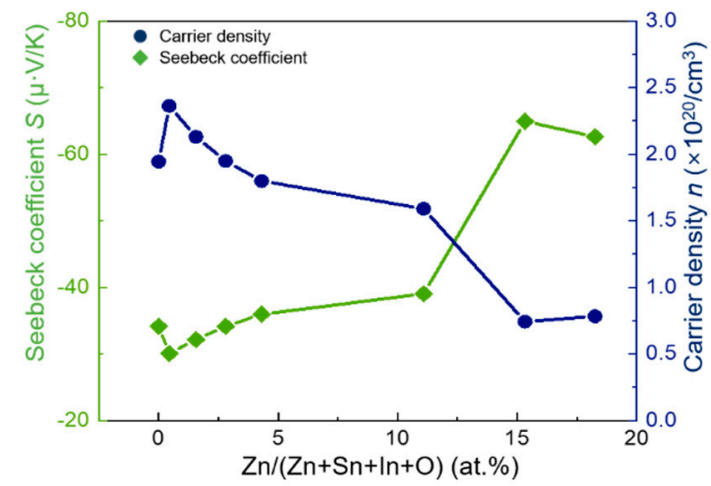

(b)

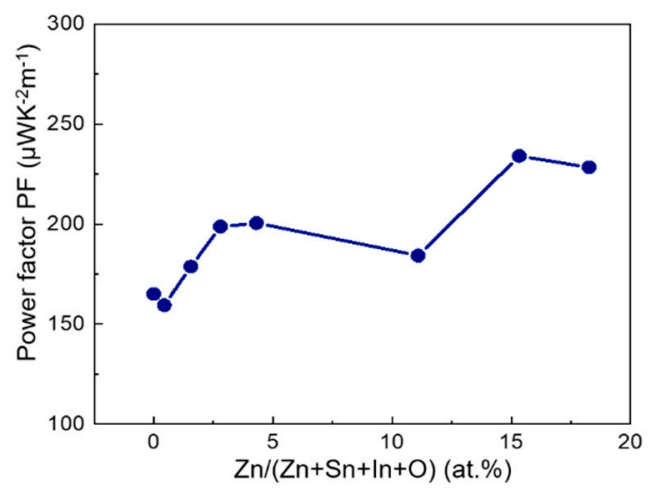

Figure 4. (a) Seebeck coefficient $(S)$ and carrier density $(n)$, (b) power factor (PF) of ITO:Zn thin films in relation to zinc concentration.

The variations in the PF values in relation to the zinc content are shown in Figure $4 \mathrm{~b}$. The TE properties can be evaluated with the PF, which depends on the $\sigma$ and $S$ values, as defined in Equation (4):

$$
\mathrm{PF}=S^{2} \sigma .
$$

It was observed that the highest PF $\left(234.03 \mu \mathrm{W} \mathrm{K} \mathrm{K}^{-2} \cdot \mathrm{m}^{-1}\right)$ was obtained when the zinc content was 15.33 at.\%, owing to the highest $S$ value caused by the lowest $n$ value, even though $\sigma$ declined. Several studies have reported on the TE performance of thin films based on only the PF value, because measuring the $\kappa$ values of the TE materials is very difficult. However, measuring $\kappa$ of the thin film is crucial to evaluate the TE performance more accurately.

Figure 5a shows the ZT values, which were evaluated using the measured $\kappa$ values of the ITO:Zn thin films, in relation to the zinc content. The highest $\mathrm{ZT}$ value of 0.0627 was obtained when the zinc content was 18.26 at. $\%$ due to the low $\kappa\left(1.085 \mathrm{Wm}^{-1} \cdot \mathrm{K}^{-1}\right)$ and high PF $\left(228.37 \mu \mathrm{W} . \mathrm{K}^{-2} \cdot \mathrm{m}^{-1}\right)$ values. It is notable that the highest $\mathrm{PF}\left(234.03 \mu \mathrm{W} \mathrm{K} \mathrm{K}^{-2} \cdot \mathrm{m}^{-1}\right)$ was obtained when the zinc content was 15.33 at. $\%$, while the highest $\mathrm{ZT}$ value was obtained for the thin films that include a zinc content of 18.26 at.\%. This phenomenon is attributed to the lowest $\kappa$ value $\left(1.085 \mathrm{~W} \mathrm{~m}^{-1} \cdot \mathrm{K}^{-1}\right)$, obtained at the zinc content of 18.26 at.\%, even if the PF at the zinc content of 18.26 at.\% $\left(228.37 \mu \mathrm{W} \mathrm{K}^{-2} \cdot \mathrm{m}^{-1}\right)$ is lower than that at the zinc content of 15.33 at. $\%\left(234.03 \mu \mathrm{W} \mathrm{K}{ }^{-2} \cdot \mathrm{m}^{-1}\right)$.

Moreover, it was confirmed that the highest ZT value of the a-ITO:Zn film (0.0627) was approximately 2.5 times higher than that of the c-ITO film (0.0252). Consequently, these results indicate that the evaluation of the TE performance through $\mathrm{ZT}$ can provide more accuracy than that 
performed using PF. Moreover, we successfully obtained a high TE performance of the thin film with an amorphous structure.

Figure $5 b$ shows $\kappa$ of the as-deposited ITO:Zn thin films as a function of the zinc concentration. The total $\kappa\left(\kappa_{t o t}\right)$ is determined by both electron thermal conductivity $\left(\kappa_{e}\right)$ and lattice thermal conductivity $\left(\kappa_{l}\right)$, i.e., $\kappa_{\text {total }}=\kappa_{e}+\kappa_{l}$. The value of $\kappa_{\text {tot }}$ decreases with an increase in the zinc concentration in ITO:Zn thin films. The value of $\kappa_{e}$ was calculated by the Wiedemann-Franz law using Equation (5).

$$
\kappa_{e}=L_{o} T / \rho,
$$

where $L_{o}, T$, and $\rho$ represent the Lorentz constant $\left(2.45 \times 10^{-8} \mathrm{~W} \Omega \mathrm{K}^{-2}\right)$, absolute temperature, and resistivity, respectively. It was observed that $n$ was mainly responsible for the decline of $\kappa_{e}$. The value of $\kappa_{l}$ increased with an increase in the zinc content, and decreased when the zinc content was under 1.56 at. $\%$. In general, an amorphous structure demonstrates minimal lattice vibrations. Therefore, the decrease of $\kappa_{l}$ is attributed to the transformation of the microstructure from crystalline to amorphous. However, despite the amorphous structure, $\kappa_{l}$ increased with an increase in the zinc concentration in the ITO thin films. These results could be attributed to two factors, including the vibration generated from the metal hydroxyl formation due to low bond enthalpy between zinc and oxygen, and the $\kappa_{l}$ improvement due to localized vibration.

On the other hand, Nickel et al. [40] reported that the hydrogen in $\mathrm{ZnO}$ vibrates in the lattice. Wöhlecke et al. [41] also reported that the hydroxyl-stretching vibration is coupled to the phonon in oxide. Therefore, we considered that the increase in $\kappa_{l}$ resulted from the vibration formed due to the increased metal hydroxide between zinc 2.80 at.\% and 15.33 at.\%. An XPS analysis was conducted to establish this phenomenon.

Figure 6a shows the XPS O 1 s spectra with fitted curves $\left(\mathrm{O}_{1}, \mathrm{O}_{2}\right.$, and $\mathrm{O}_{3}$ sub-peaks) by Gaussian. The $\mathrm{O}_{1}$ sub-peak ( $529.24 \mathrm{eV}$ ) is attributed to the oxygen-bonded metal in lattice, and the $\mathrm{O}_{2}$ sub-peak $(530.09 \mathrm{eV})$ is attributed to the oxygen-deficient regions related to oxygen vacancies. $\mathrm{Th} \mathrm{O}_{3}$ sub-peak $(531.13 \mathrm{eV})$ results from the chemisorbed oxygen related to the formation of metal hydroxide [42-46]. Figure $6 \mathrm{~b}$ shows the relative area ratio of $\mathrm{O}_{1}, \mathrm{O}_{2}$, and $\mathrm{O}_{3}$ peaks obtained from the ITO:Zn thin films with varied zinc content. As shown in Figure 3, the $\mathrm{O}_{2}$ peak area ratio, implying oxygen vacancies, relatively decreased, leading to a decrease in $n$, when the zinc content was over 0.44 at. $\%$. The $\mathrm{O}_{3}$ peak area ratio was almost constant at higher zinc content. As a result, the amount of metal hydroxide did not change with increasing zinc content. The FT-IR analysis was conducted to confirm the presence of $\mathrm{OH}$ vibration.

Figure 7 shows the FT-IR spectra of ITO:Zn thin films for varied zinc content against the wavenumbers ranging from 650 to $4000 \mathrm{~cm}^{-1}$ at room temperature (RT). The peaks at 906.56-925.31 $\mathrm{cm}^{-1}$ are related to atoms that are still unoxidized [47]. The peaks at $1023.49-1026.37 \mathrm{~cm}^{-1}$ are related to the phonon mode of the $\operatorname{In}_{2} \mathrm{O}_{3}$ lattice [47]. The OH-stretching vibration mode is related to a wavenumber around $3240 \mathrm{~cm}^{-1}$ [47-52]. It was expected that the $\mathrm{OH}$-stretching vibration would increase as the zinc content in the films increased.

However, no significant differences of absorbance were observed in the wavenumber range mentioned. Based on these results, it was observed that the $\mathrm{OH}$-stretching vibration exerted only a minimal influence. Another cause of an increase in $\kappa_{l}$ could possibly be the vibration formed through the short-range order in the amorphous structure, called the localized region. Therefore, it was confirmed that the vibration through the localized region contributed to the increase in $\kappa_{l}$ in the amorphous structure rather than the vibration formed through coupling with hydroxyl and phonon in the lattice. 
(a)

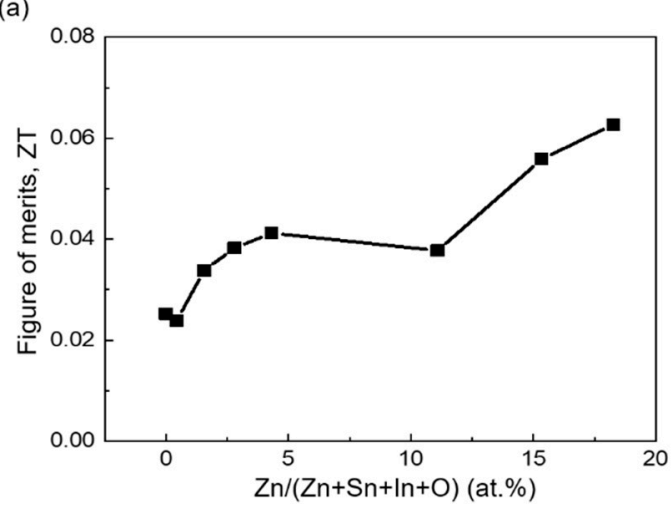

(b)

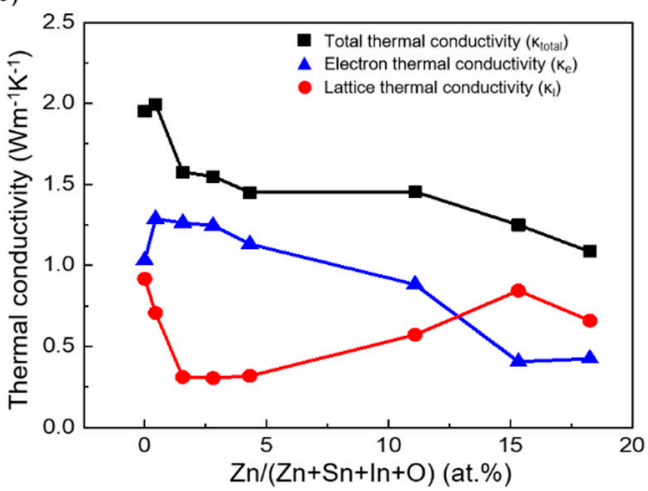

Figure 5. (a) ZT values for the as-deposited ITO:Zn thin films, and (b) thermal conductivity as a function of zinc content ratio.

(a)

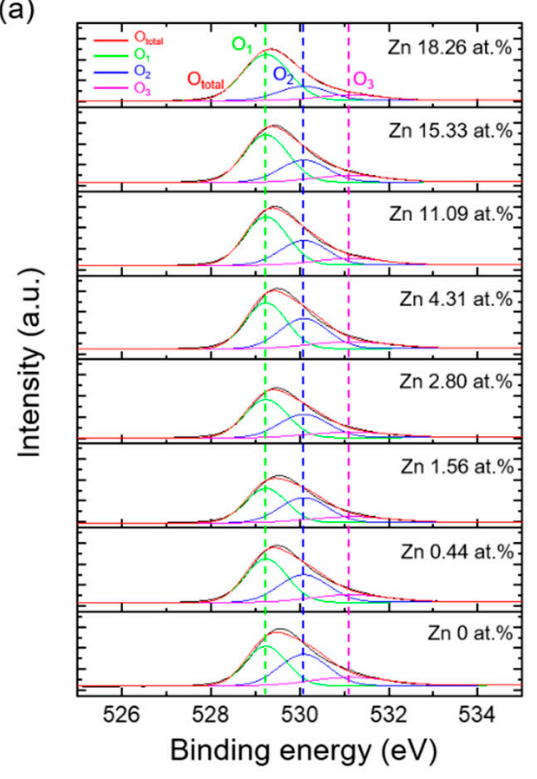

(b)

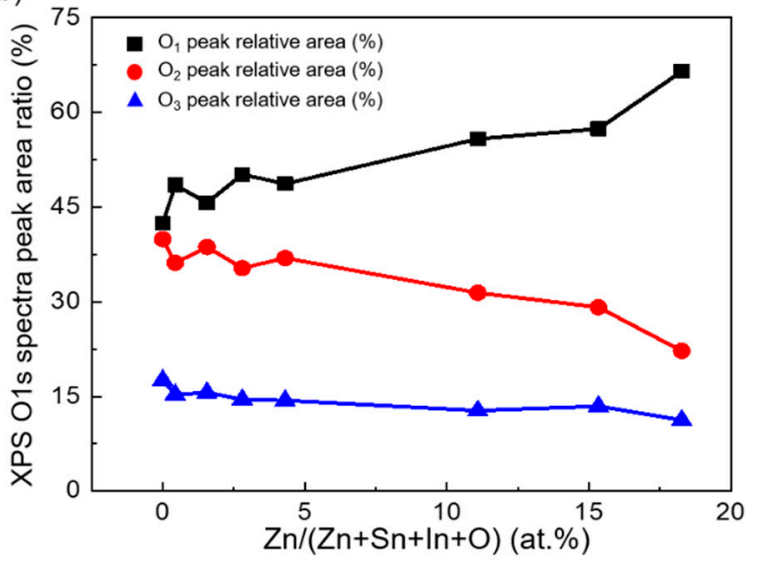

Figure 6. (a) X-ray photoelectron spectroscopy (XPS) $\mathrm{O} 1$ s spectra with fitted curves $\left(\mathrm{O}_{1}, \mathrm{O}_{2}\right.$, and $\left.\mathrm{O}_{3}\right)$, (b) relative area ratio of $\mathrm{O}_{1}, \mathrm{O}_{2}$, and $\mathrm{O}_{3}$ peaks obtained from ITO:Zn thin films with varied zinc content.

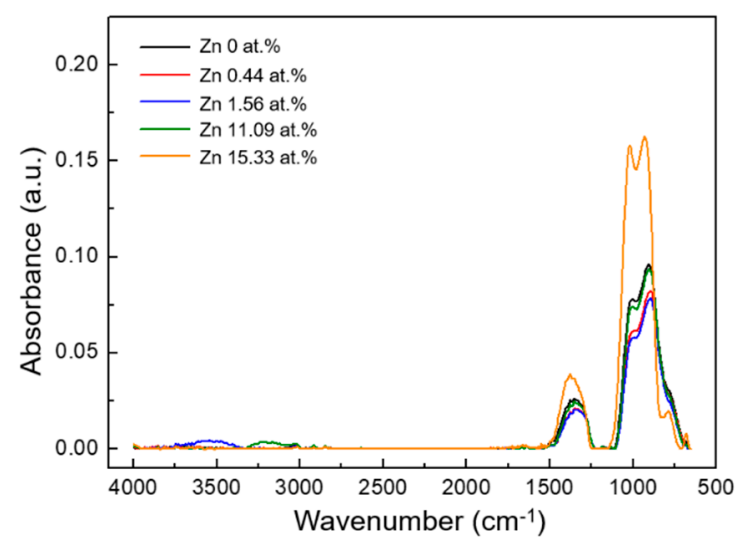

Figure 7. Fourier transform-infrared spectra of zinc-doped In-Sn-O thin films for different zinc content in the wavenumber range of $650-4000 \mathrm{~cm}^{-1}$ at RT. 


\section{Conclusions}

In this study, the ITO:Zn thin films were deposited through magnetron co-sputtering, by controlling the $\mathrm{ZnO}$ RF power to investigate the TE properties of these thin films. From experiments, it was observed that the ITO:Zn thin films demonstrated a crystalline structure without substrate heating and were amorphized when the zinc content was over 1.56 at.\%. The ITO:Zn films demonstrated a high transmittance in the visible wavelength $(>85 \%$ at $550 \mathrm{~nm})$. The highest $Z T$ value of 0.0627 was obtained when the zinc content was 18.26 at.\% due to the lowest $\kappa$ value $\left(1.085 \mathrm{~W} \mathrm{~m}^{-1} \cdot \mathrm{K}^{-1}\right)$, even though the PF at the zinc content of $18.26 \%\left(228.37 \mu \mathrm{W} \mathrm{K}^{-2} \cdot \mathrm{m}^{-1}\right)$ was lower than that at the zinc content of $15.33 \%$ $\left(234.03 \mu \mathrm{W} \mathrm{K} \mathrm{K}^{-2} \cdot \mathrm{m}^{-1}\right)$. It was also confirmed that the highest ZT value of the a-ITO:Zn film (0.0627) was approximately 2.5 times higher than that of the c-ITO film (0.0252). Consequently, the evaluation of TE properties performed with ZT values was observed to be more accurate than that performed with PF values. Moreover, we successfully obtained a high TE performance of thin films with an amorphous structure. We confirmed that the increase in $\kappa_{l}$ in an amorphous structure with substantial zinc content could be attributed to the localized mode in the amorphous structure. Based on these properties, it is suggested that amorphous ITO:Zn thin films can be applied as high-performance TE materials in transparent display devices.

Author Contributions: Conceptualization, H.Y.L., S.K., and P.K.S.; Formal analysis, I.J.Y. and J.-H.Y.; Funding acquisition, S.-H.J. and P.K.S.; Project administration P.K.S.; Investigation, H.Y.L.; Writing-original draft preparation, H.Y.L.; Writing—review and editing, S.K. and P.K.S.; Supervision, S.K. and P.K.S.

Funding: This work was funded by National Research Foundation of Korea grants (No. 2017R1A2B4012144 and 2018R1A5A1025594) and partially financially supported by the Ministry of the Environment (G232019012551).

Conflicts of Interest: The authors declare no conflicts of interest.

\section{References}

1. Gayner, C.; Kar, K.K. Recent advances in thermoelectric materials. Prog. Mater. Sci. 2016, 83, 330-382. [CrossRef]

2. Ismail, B.; Ahmed, W. Thermoelectric Power Generation Using Waste-Heat Energy as an Alternative Green Technology. Recent Pat. Electr. Eng. 2009, 2, 27-39. [CrossRef]

3. Bell, L.E. Cooling, Heating, Generating Power, and Recovering Waste Heat with Thermoelectric Systems. Science 2008, 321, 1457-1461. [CrossRef]

4. Jeffrey, G.J.; Toberer, E.S. Complex thermoelectric materials. In Materials for Sustainable Energy; Nature Publishing Group: London, UK, 2010; pp. 105-114.

5. Liu, W.; Yan, X.; Chen, G.; Ren, Z. Recent advances in thermoelectric nanocomposites. Nano Energy 2012, 1, 42-56. [CrossRef]

6. Tritt, T.M.; Subramanian, M.A. Thermoelectric Materials, Phenomena, and Applications: A Bird's Eye View. MRS Bull. 2006, 31, 188-198. [CrossRef]

7. Gross, A.J.; Hwang, G.S.; Huang, B.; Yang, H.; Ghafouri, N.; Kim, H.; Peterson, R.L.; Uher, C.; Kaviany, M.; Najafi, K. Multistage planar thermoelectric microcoolers. J. Microelectromechan. Syst. 2011, 20, 1201-1210. [CrossRef]

8. Snyder, G.J;; Soto, M.; Alley, R.; Koester, D.; Conner, B. Hot Spot Cooling using Embedded Thermoelectric Coolers. In Proceedings of the 22nd Annual IEEE Semiconductor Thermal Measurement and Management Symposium, Dallas, TX, USA, 14-16 March 2006; pp. 135-143.

9. Nam, W.H.; Lim, Y.S.; Choi, S.-M.; Seo, W.-S.; Lee, J.Y. High-temperature charge transport and thermoelectric properties of a degenerately Al-doped $\mathrm{ZnO}$ nanocomposite. J. Mater. Chem. 2012, 22, 14633-14638. [CrossRef]

10. Jeong, M.-W.; Na, S.; Shin, H.; Park, H.-B.; Lee, H.-J.; Joo, Y.-C. Thermomechanical in situ monitoring of $\mathrm{Bi}_{2} \mathrm{Te}_{3}$ thin film and its relationship with microstructure and thermoelectric performances. Electron. Mater. Lett. 2018, 14, 426-431. [CrossRef]

11. Hong, J.E.; Lee, S.K.; Yoon, S.G. Enhanced thermoelectric properties of thermal treated $\mathrm{Sb}_{2} \mathrm{Te}_{3}$ thin films. J. Alloys Compd. 2014, 583, 111-115. [CrossRef] 
12. Goncalves, L.M.; Couto, C.; Alpuim, P.; Rolo, A.G.; Völklein, F.; Correia, J.H. Optimization of thermoelectric properties on $\mathrm{Bi}_{2} \mathrm{Te}_{3}$ thin films deposited by thermal co-evaporation. Thin Solid Films 2010, 518, $2816-2821$. [CrossRef]

13. Loureiro, J.; Neves, N.; Barros, R.; Mateus, T.; Santos, R.; Filonovich, S.; Reparaz, S.; Sotomayor-Torres, C.M.; Wyczisk, F.; Divay, L.; et al. Transparent aluminium zinc oxide thin films with enhanced thermoelectric properties. J. Mater. Chem. A 2014, 2, 6649-6655. [CrossRef]

14. Korotcenkov, G.; Brinzari, V.; Cho, B.K. $\mathrm{In}_{2} \mathrm{O}_{3}$-based multicomponent metal oxide films and their prospects for thermoelectric applications. Solid State Sci. 2016, 52, 141-148. [CrossRef]

15. Tuna, O.; Selamet, Y.; Aygun, G.; Ozyuzer, L. High quality ITO thin films grown by DC and RF sputtering without oxygen. J. Phys. D Appl. Phys. 2010, 43, 055402. [CrossRef]

16. Zhang, K.; Zhu, F.; Huan, C.H.A.; Wee, A.T.S. Indium tin oxide films prepared by radio frequency magnetron sputtering method at a low processing temperature. Thin Solid Films 2000, 376, 255-263. [CrossRef]

17. Kim, S.; Yoon, J.-H.; Bang, J.; Song, P. Effect of hydrogen on mechanical stability of amorphous In-Sn-O thin films for flexible electronics. Thin Solid Films 2019, 669, 275-280. [CrossRef]

18. Santos, R.; Loureiro, J.; Nogueira, A.; Elangovan, E.; Pinto, J.V.; Veiga, J.P.; Busani, T.; Fortunato, E.; Martins, R.; Ferreira, I. Thermoeletcric properties of $\mathrm{V}_{2} \mathrm{O}_{5}$ thin films deposited by thermal evaporation. Appl. Surf. Sci. 2013, 282, 590-594. [CrossRef]

19. Li, L.; Fang, L.; Chen, X.M.; Liu, J.; Yang, F.F.; Li, Q.J.; Liu, G.B.; Feng, S.J. Influence of oxygen argon ratio on the structural, electrical, optical and thermoelectrical properties of Al-doped ZnO thin films. Physica E 2008, 41, 169-174. [CrossRef]

20. Saini, S.; Mele, P.; Honda, H.; Suzuki, T.; Matsumoto, K.; Miyazaki, K.; Ichinose, A.; Molina-Luna, L.; Carlini, R.; Tiwari, A. Effect of self-grown seed layer on thermoelectric properties of ZnO thin films. Thin Solid Films 2016, 605, 289-294. [CrossRef]

21. Saini, S.; Mele, P.; Honda, H.; Henry, D.J.; Hopkins, P.E.; Molina-Luna, L.; Matsumoto, K.; Miyazaki, K.; Ichinose, A. Enhanced thermoelectric performance of Al-doped $\mathrm{ZnO}$ thin films on amorphous substrate. Jpn. J. Appl. Phys. 2014, 53, 1-4. [CrossRef]

22. Saini, S.; Mele, P.; Honda, H.; Matsumoto, K.; Miyazaki, K.; Luna, L.M.; Hopkins, P.E. Influence of Postdeposition Cooling Atmosphere on Thermoelectric Properties of 2\% Al-Doped ZnO Thin Films Grown by Pulsed Laser Deposition. J. Electron. Mater. 2015, 44, 1547-1553. [CrossRef]

23. Brinks, P.; Heijmerikx, H.; Hendriks, T.A.; Rijnders, G.; Huijben, M. Achieving chemical stability in thermoelectric $\mathrm{Na}_{x} \mathrm{CoO}_{2}$ thin films. R. Soc. Chem. 2012, 2, 6023-6027. [CrossRef]

24. Byeon, J.; Kim, S.; Lim, J.H.; Song, J.Y.; Park, S.H.; Song, P. Thermoelectric and electrical properties of micro-quantity Sn-doped amorphous indium-zinc oxide thin films. Jpn. J. Appl. Phys. 2017, 56, 1-3. [CrossRef]

25. Jha, P.; Sands, T.D.; Jackson, P.; Bomberger, C.; Favaloro, T.; Hodson, S.; Zide, J.; Xu, X.; Shakouri, A. Cross-plane thermoelectric transport in p-type $\mathrm{La}_{0.67} \mathrm{Sr}_{0.33} \mathrm{MnO}_{3} / \mathrm{LaMnO}_{3}$ oxide metal/semiconductor superlattices. J. Appl. Phys. 2013, 53, 1-8. [CrossRef]

26. Robert, R.; Aguirre, M.H.; Bocher, L.; Trottmann, M.; Heiroth, S.; Lippert, T.; Do, M.; Weidenkaff, A. Thermoelectric properties of $\mathrm{LaCo}_{1-x} \mathrm{Ni}_{x} \mathrm{O}_{3}$ polycrystalline samples and epitaxial thin films. Solid State Sci. 2008, 10, 502-507. [CrossRef]

27. Nguyen, N.H.T.; Nguyen, T.H.; Liu, Y.-R.; Aminzare, M.; Pham, A.T.T.; Cho, S.; Wong, D.P.; Chen, K.-H.; Seetawan, T.; Pham, N.K.; et al. Thermoelectric properties of indium and gallium dually doped $\mathrm{ZnO}$ thin films. ACS Appl. Mater. Interfaces 2016, 8, 33916-33923. [CrossRef]

28. Kim, S.; Kim, D.; Byeon, J.; Lim, J.; Song, J.; Park, S.; Park, C.; Song, P. Transparent amorphous oxide semiconductor as excellent thermoelectric materials. Coatings 2018, 8, 462. [CrossRef]

29. Vogel-Schäuble, N.; Romanyuk, Y.E.; Yoon, S.; Saji, K.J.; Populoh, S.; Pokrant, S.; Aguirre, M.H.; Weidenkaff, A. Thermoelectric properties of nanostructured Al-substituted ZnO thin films. Thin Solid Films 2012, 520, 6869-6875. [CrossRef]

30. Kang, J.G.; Hong, K.S.; Yang, H.S. Investigation of film-thickness dependent thermal conductivity of $\mathrm{Gd}_{2} \mathrm{Zr}_{2} \mathrm{O}_{7}$ thin films. Curr. Appl. Phys. 2013, 13, 1967-1970. [CrossRef]

31. Cahill, D.G.; Ford, W.K.; Goodson, K.E.; Mahan, G.D.; Majumdar, A.; Maris, H.J.; Merlin, R.; Phillpot, S.R. Nanoscale thermal transport. Appl. Phys. Rev. 2003, 93, 793-818. [CrossRef] 
32. Kim, D.-H.; Lee, G.-W.; Kim, Y.-C. Interaction of zinc interstitial with oxygen vacancy in zinc oxide: An origin of n-type doping. Solid State Commun. 2012, 1711-1714. [CrossRef]

33. Telephone, B.; Thomas, D.G. Interstitial zinc in zinc oxide. J. Phys. Chem. Solids 1957, 3, 229-237.

34. Carreras, P.; Antony, A.; Roldán, R.; Nos, O.; Frigeri, P.A.; Asensi, J.M.; Bertomeu, J. Transparent conducting thin films by co-sputtering of ZnO-ITO targets. Phys. Status Solidi 2010, 7, 953-956. [CrossRef]

35. Film, C.; Liu, D.; Wu, C.; Lee, T. Electrical, optical and material properties of ZnO-doped indium-tin oxide films prepared using radio frequency magnetron cosputtering system at room temperature. Jph. J. Appl. Phys. 2006, 45, 3526-3530.

36. Kwon, S.H.; Jung, J.H.; Cheong, W.S.; Lee, G.H.; Song, P.K. Dependence of electrical and mechanical durability on Zn content and heat treatment for co-sputtered ITZO films. Curr. Appl. Phys. 2012, 12, S59-S63. [CrossRef]

37. Putri, M.; Kim, K.H.; Koo, C.Y.; Lee, J.; Kim, J.; Baikie, I.D.; Grain, A.C.; Lee, H.Y. Effect of annealing treatment on the properties of stoichiometric indium zinc tin oxide (IZTO) thin films. J. Nanoelectron. Optoelectron. 2017, 12, 611-616. [CrossRef]

38. Minami, T.; Yamamoto, T.; Toda, Y.; Miyata, T. Transparent conducting zinc-co-doped ITO films prepared by magnetron sputtering. Thin Solid Films 2000, 373, 189-194. [CrossRef]

39. Hwang, M.-S.; Jeong, H.S.; Kim, W.M.; Seo, Y.W. Properties of Co-deposited indium tin oxide and zinc oxide films using a bipolar pulse power supply and a dual magnetron sputter source. Am. Vac. Soc. 2003, 21, 1399-1403. [CrossRef]

40. Nickel, N.H.; Fleischer, K. Hydrogen local vibrational modes in zinc oxide. Am. Phys. Sonciety 2003, 90, 1-4. [CrossRef]

41. Wöhlecke, M.; Kovács, L. OH ${ }^{-}$ions in Oxide Crystals. Crit. Rev. Solid State Mater. Sci. 2001, 25, 1-86. [CrossRef]

42. Heo, G.-S.; Matsumoto, Y.; Gim, I.-G.; Park, J.-W.; Kim, K.-Y.; Kim, T.-W. Fabrication of cosputtered $\mathrm{Zn}-\mathrm{In}-\mathrm{Sn}-\mathrm{O}$ films and their applications to organic light-emitting diodes. Solid State Commun. 2009, 149, 1731-1734. [CrossRef]

43. Zhong, W.; Li, G.; Lan, L.; Li, B.; Chen, R. Effects of annealing temperature on properties of InSnZnO thin film transistors prepared by Co-sputtering. RSC Adv. 2018, 8, 34817-34822. [CrossRef]

44. Carreras, P.; Gutmann, S.; Antony, A.; Bertomeu, J.; Schlaf, R.; Carreras, P.; Gutmann, S.; Antony, A.; Bertomeu, J.; Schlaf, R. The electronic structure of co-sputtered zinc indium tin oxide thin films. J. Appl. Phys. 2011, 110, 073711. [CrossRef]

45. Stoev, M.; Toušková, J.; Tousek, J. X-ray photoelectron spectroscopy, scanning electron microscopy and optical transmittance studies of indium tin oxide and cadmium sulphide thin films for solar cells. Thin Solid Films 1997, 299, 67-71. [CrossRef]

46. Donley, C.; Dunphy, D.; Paine, D.; Carter, C.; Nebesny, K.; Lee, P.; Alloway, D.; Armstrong, N.R. Characterization of indium-tin oxide interfaces using $\mathrm{X}$-ray photoelectron spectroscopy and redox processes of a chemisorbed probe molecule: Effect of surface pretreatment conditions. Langmuir 2002, 18, 450-457. [CrossRef]

47. Zhu, G.; Guo, L.; Shen, X.; Ji, Z.; Chen, K.; Zhou, H. Monodispersed $\operatorname{In}_{2} \mathrm{O}_{3}$ mesoporous nanospheres: One-step facile synthesis and the improved gas-sensing performance. Sens. Actuators B Chem. 2015, 220, 977-985. [CrossRef]

48. Abbasi, M.; Rozati, S.M. Deposition of nanostructured indium oxide thin films for ethanol sensing applications. J. Electron. Mater. Mater. 2016, 45, 2855-2860. [CrossRef]

49. Thirumoorthi, M.; Thomas Joseph Prakash, J. Structure, optical and electrical properties of indium tin oxide ultrathin films prepared by jet nebulizer spray pyrolysis technique. J. Asian Ceram. Soc. 2016, 4, 124-132. [CrossRef]

50. Chandradass, J.; Bae, D.S.; Kim, K.H. A simple method to prepare indium oxide nanoparticles: Structural, microstructural and magnetic properties. Adv. Powder Technol. 2011, 22, 370-374. [CrossRef]

51. Körösi, L.; Papp, S.; Dékány, I. Preparation of transparent conductive indium tin oxide thin films from nanocrystalline indium tin hydroxide by dip-coating method. Thin Solid Films 2011, 519, 3113-3118. [CrossRef]

52. Song, P.; Han, D.; Zhang, H.; Li, J.; Yang, Z.; Wang, Q. Hydrothermal synthesis of porous $\operatorname{In}_{2} \mathrm{O}_{3}$ nanospheres with superior ethanol sensing properties. Sens. Actuators B Chem. 2014, 196, 434-439. [CrossRef]

(C) 2019 by the authors. Licensee MDPI, Basel, Switzerland. This article is an open access article distributed under the terms and conditions of the Creative Commons Attribution (CC BY) license (http://creativecommons.org/licenses/by/4.0/). 